\title{
Research through the Generations: Reflecting on the Past, Present and Future
}

\author{
Gráinne Conole ${ }^{1}$ \\ Consultant \& Visiting Professor of Dublin City University, Dublin, Ireland
}

(Received April 2017; final version received May 2017)

\begin{abstract}
The paper provides a reflection on the past and present of research on the use of digital technologies for learning, teaching and research, along with an extrapolation of the future of the field. It considers which technologies have been transformative in the last thirty years or so along with the nature of the transformation and the challenges. Research in the field is grouped into three types: pedagogical, technical and organizational. The emergence and nature of digital learning as a field is considered. Six facets of digital learning, and in particular digital technologies, as a research field are described: the good and the bad of digital technologies, the speed of change, the new forms of discourse and collaboration, the importance of understanding users, the new practices that have emerged, and finally a reflection on the wider impact.
\end{abstract}

\section{Introduction}

On the $1^{\text {st }}$ November 2016 Dublin City University hosted 'The next generation digital learning research symposium.' This paper fleshes out the keynote given as part of the symposium. The title I was given 'Research through the generations: reflecting on the past, present and future, was an interesting and challenging focus. In particular looking back at the emergence of a field is useful and can give an indication of where the field is going in the near future.

\section{Emergent technologies}

A number of reports track emergent technologies. Perhaps the best know is the New Media Consortium Horizon report series (NMC, 2016). The 2016 report for Higher Education indicates which technologies are likely to have the most impact in one, three and five years time, along with trends in the short, medium and long term.

${ }^{1}$ Corresponding author. Email: gconole@gmail.com

Irish Journal of Technology Enhanced Learning Ireland, 2017. (C) 2017 G Conole. The Irish Journal of Technology Enhanced Learning Ireland is the journal of the Irish Learning Technology Association, an Irishbased professional and scholarly society and membership organisation. (CRO\# 520231) http://www.ilta.ie/ . This is an Open Access article distributed under the terms of the Creative Commons Attribution 4.0 International License (http://creativecommons.org/licenses/by/4.0), allowing third parties to copy and redistribute the material in any medium or format and to remix, transform, and build upon the material for any purpose, even commercially, provided the original work is properly cited and states its license. 


\section{G. Conole}

In one year's time bring your own device and learning analytics/adaptive learning are likely to be most important. In three years' time augmented and virtual reality and makerspaces are listed. The concept of makerspaces needs unpacking. The question of how to renovate or repurpose classrooms and labs to address the needs of the future is being answered through the concept of makerspaces, which offers tools and learning experiences to help people carry out their ideas. The driving force behind makerspaces is rooted in the maker movement, a following comprised of artists, technology enthusiasts, engineers, builders, and people with a passion for making things. And in five years' time affective computing and robotics are likely to have the most impact.

In terms of trends, in the short-term there is likely to be a growing focus on measuring learning and on increased use of blended learning designs. In the mid-term, redesigning learning spaces and a shift to deeper learning approaches will be the focus. In the long-term advancing cultures of innovation and rethinking how institutions work will be important.

Solvable challenges are blending formal and informal learning, and improving digital literacy. Difficult challenges include dealing with competing models of education and personalized learning. Finally, wicked challenges include balancing our connected and unconnected lives, and keeping education relevant.

The Open University UK have an innovating pedagogy series of reports, which describe ten ways in which digital technologies are going to affect education (Innovating Pedagogy, 2016). The report identifies the following as the best ways of facilitating learning to equip learners for the future: cooperative learning, collaborative and social learning, feedback for learning, active and constructive learning.

The first is learning through social media, which reflects the increasing importance of social media in education. This is particularly relevant for learning outside of the formal learning context. Tools such as Twitter and Facebook are being used to share ideas and engage in conversations, enabling learners to access expert advice and receive feedback on ideas so that these can be improved. However, a downside of social media is separating useful information from 'white noise' and having the digital literacy skills to assess whether information found is relevant, correct and of good quality.

The second is productive failure, not a new concept, but one that has developed in the digital age. This method of teaching gives learners complex problems to solve; by struggling and sometimes failing to find a solution, learners gain a deeper understanding of the nature of the problem. The focus is about embracing challenge and uncertainty; important skills learners need to develop. We are educating learners who face an uncertain but constantly changing future, and who will be doing jobs that do not even exist today. Therefore, we need to shift the focus from knowledge recall to development of transferable skills and competences, such as critical thinking, problem solving, and team work.

The third is 'teachback' where learners learn from each other. One person (who may be a teacher, an expert, or another student) explains their knowledge of a topic to a learner. Then, that learner attempts to explain, or teach back, what they have understood. This offers two benefits. It helps learners to understand a topic or problem by reframing it in their own terms. They also need to explain what they have learned in a way that is understandable. 
Design thinking is listed as the forth innovation. Design thinking solves problems using the methods and thinking processes used by designers. These include creative processes such as experimenting, creating and prototyping models, soliciting feedback and redesigning. Again these are all important transferable skills that are needed to equip learners for the future.

The fifth is learning from a crowd. Through social media learners are now part of a global community of peers and experts, providing them with unprecedented access to information and expertise. Crowdsourcing can be used to collect and curate learning and teaching resources, and provide learners with opportunities to share and discuss their work.

Learning through video games is listed as the sixth innovation. It has long being known that games can make learning fun, interactive and stimulating (Gee, 2003). So it is interesting to note that both productive failure and making learning fun are important and when designing learning interactions it is important to give consideration to what is the appropriate balance to these two seemingly counter-intuitive concepts.

The importance of learning analytics as a new branch of research the use of digital technologies for education has emerged in recent years (Ferguson, 2013). The focus to date has been on measuring and predicting the learning processes of learners by tracing their behaviour and making inferences about their learning. Summative learning analytics enables teachers to identify which learners might need support. The seventh innovation in the report highlights formative analytics, where the focus is use of the analytics by the learner. The analytics can help the learner reflect on what they have learned, and enable them to set and measure progress against their learning goals, as well as identify what can be improved.

The report argues that 'learners need to be educated not just for today but for the future. They should acquire skills and dispositions that will enable them to cope with an uncertain life and a complex work environment'. Hence the eight innovation is a focus on learning for the future. Therefore the focus shifts from knowledge recall to helping learners develop transferable skills such as critical thinking and problem solving and to help them to learn, unlearn and relearn.

An interesting concept of 'translanguaging' is listed as the ninth innovation, which refers to the ability to move flexibly and fluidly between languages. Many argue that learners develop different cognitive skills when learning languages (Deák, 2014). However, it is interesting to see how this concept develops as automatic language translation tools become increasingly sophisticated (Henry, 2014).

The final innovation is the concept of 'blockchain' learning. A blockchain stores digital events securely on every user's computer rather than in a central database. Blockchain learning explores how this approach could be applied to education, shifting from central records of student performance held by schools and universities to a more democratic model in which achievements are recorded by a wider range of participants. Blockchain technology allows any participant to add a new record such as an exam score to a single digital chain of events. This chain is stored across many computers, yet cannot be altered or undone. This arguably has the potential to transform education, enabling a learner to control their learning and demonstration of achievement of learning outcomes, and helps learners become lifelong learners. 


\section{G. Conole}

\section{Transformative technologies}

Figure 1 shows an e-learning timeline of the technologies that have had the most impact on education over the last thirty years or so, from the emergence of tools for creating rich multimedia learning through to learning analytics to help teachers better support their learners and to help learners better understand how they are learning and to help them improve their learning strategies. Arguably these have had a transformative impact on education, changing the way we learn and teach. The concept of transformation refers to something that causes a marked change in something or someone. And it is interesting to reflect on the fact that transformation is an inherent characteristic of learning. Laurillard (1993) argues that

Knowledge is information already transformed: selected, analyzed, interpreted, integrated, articulated, tested evaluated (1993: 123).

The notion of transformative technologies can be traced back to McLuhan's seminal work 'Understanding media' (McLuhan, 1964). He argued that we cannot learn anything of importance about a media by looking at its content, and that instead it is important to explore how the technological characteristics of the medium shape our lives. He argues that:

The medium is the message. This is merely to say that the personal and social consequences of any medium-- that is, of any extension of ourselves -- result from the new scale that is introduced into our affairs by each extension of ourselves, or by any new technology (1996: 7).

The concept of transformative technologies can be related to the concept of disruptive innovation developed by Christensen (1997). Although controversial it is a useful concept as it also emphasizes transformation, as well as the idea of disruption and in particular disruption of the established. In educational terms, disruptive technologies challenge the established in terms of: practices (thinking about how technologies have enabled more open practices through social media, and how this has changed the way learners access information and communicate with others), business models (in a world where content and expertise is available for free through OER and MOOCs, what are the implications for traditional institutions?), and pedagogies (what new pedagogies are arising as a result of technologies and what new pedagogies are needed to prepare learners for the future)? 


\section{E-Learning timeline}

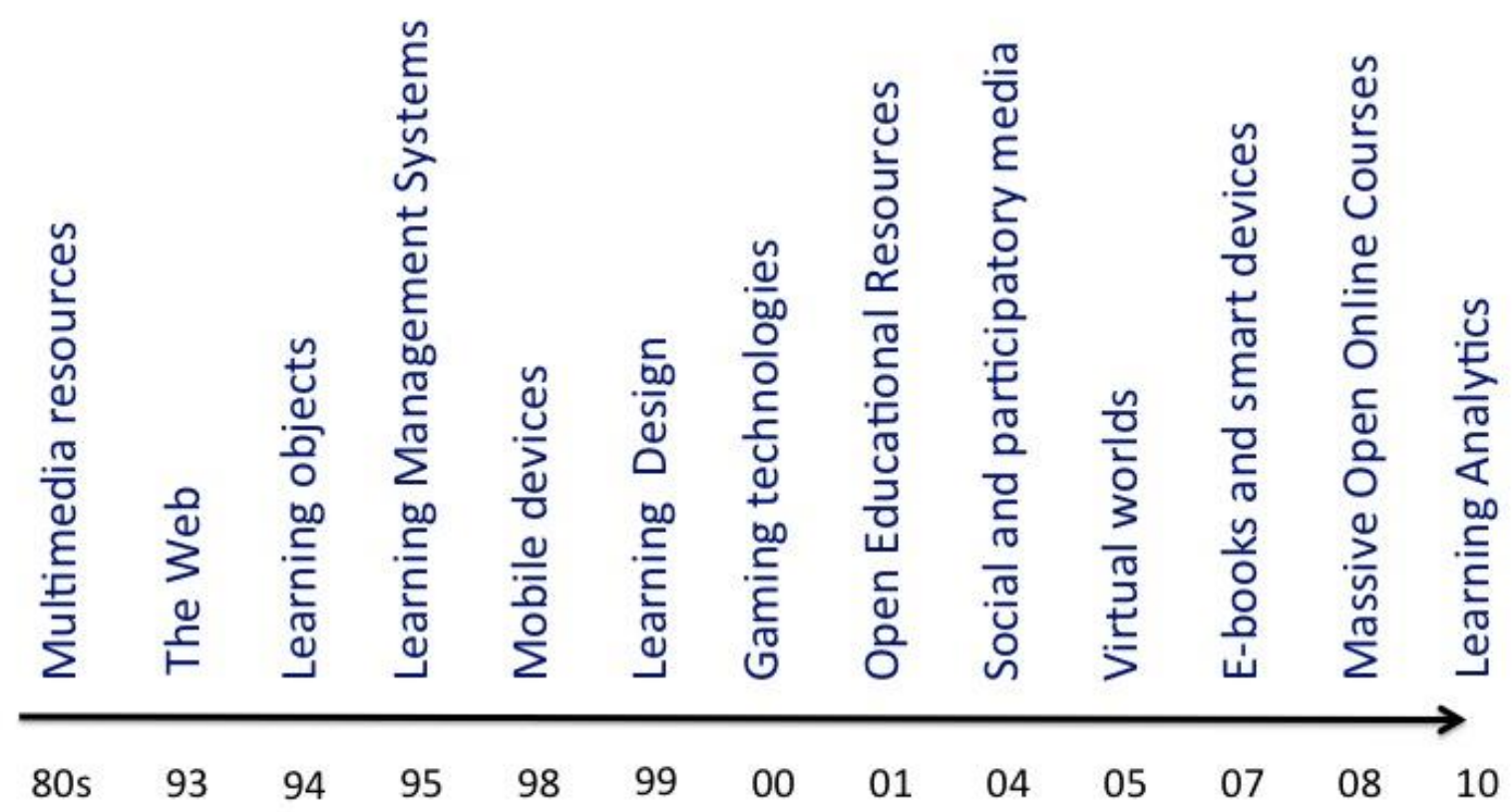

Figure 1: An e-learning timeline of transformative technologies

Table 1 lists five examples of disruptive technologies and what they have replaced. These result in new practices. For example, the emergence of word processors meant that text did not have to been written in perfect form, text could be 'cut and pasted' and moved around, resulting in a different way of writing and cognitive development. Owston et al. (1992) explored the effect of word processing on students' writing quality and revision strategies. Wikipedia has replaced paper-based encyclopedias, providing an ongoing body of knowledge created by thousands of participants. Wikis more generally are great tools for collaborative learning and co-construction of knowledge. Tools like Google drive are increasingly replacing standalone office software and again are great tools for collaboration. Mobile phones have practically replaced landlines, and mean that learning anywhere, anytime is now a reality. Finally, if not replacing exactly, OER and MOOCs are complementing existing resources and courses.

\begin{tabular}{|l|l|}
\hline Disruptive innovation & Replacing \\
\hline Word processers & Typewriters \\
\hline Wikipedia & Encyclopedias \\
\hline Google drive & Office software \\
\hline Mobile phones & Landlines \\
\hline OER/MOOCs & Resources and courses \\
\hline
\end{tabular}

Table 1: Examples of disruptive technologies

\section{Five transformative technologies}




\section{G. Conole}

The talk focused on five relatively recent transformative technologies: the web/WI-FI, Learning Management Systems (LMSs), mobile devices, Open Educational Resources (OER) and Massive Open Online Courses (MOOCs), and social media, and consider what were the characteristics that made them transformative, along with the challenges to their use. The transformative characteristics of these technologies include: access to rich interactive resources, immediacy, many ways to communicate and collaborate, enabling more open practices, and portability across devices and locations.

\subsection{The web/WI-FI}

The web has transformed every aspect of our lives; from looking up information, to booking services online, to learning through online resources and courses, to communicating with family and peers globally. It is amazing to think that the web is less than 25 years old. The web, and in particular social media has empowered individuals, enabling them to have access to information that they would not have been able to access in the past. The participatory nature of social media means that users are no longer passive recipients but active producers of information. Some of the advantages of the web include: it enables access to mainly free information, there is now a relatively low cost of connection, it facilitates rapid interactive communication, it enables the exchange of high volumes of data, it is accessible anywhere, and it has become a global media. ${ }^{2}$ Practically all organisations have some level of webpresence and searching the web is usually the first way in which people find out about an organization, for example a student making decisions about which courses to take and which institution to go to, or an applicant looking at a company's website.

Given the importance of the web, access is crucial and we now expect near ubiquitous access. Public services and private organisations alike have recognized the importance of good WIFI. For example most hotels provide free access to WI-FI, WI-FI is increasingly available on trains and even planes, and most homes have their own WI-FI network. The advantages of WI-FI include: convenience - enabling users to access content and communicate from a variety of sources via different mobile and laptop devices, mobility - users can not just get online from their workplace or home, but in hotels and coffee shops, productivity - enabling users to carry on doing work-related activities from a variety of locations, cost - wireless networking hardware is not expensive and hence is accessible to most. ${ }^{3}$

\subsection{Learning Management Systems}

The year 1993 marked a watershed in terms of the emergence of Learning Management Systems (LMSs), which provided holistic learning environments that mirrored teacher practice in terms of how they support learning. LMSs consist of a set of tools to enable teachers and learners to: upload content, communicate and collaborate, and to provide a mechanism for uploading and providing feedback on assignments. In addition, LMSs now have a rich set of learning analytics tools to provide teacher and learners with feedback on learner interactions in the system and progression. LMSs were important because they enabled teachers to create holistic learning environments for their learners, but also they

\footnotetext{
${ }^{2}$ Adapted from https://lorenapomposodraft.wordpress.com/2008/10/16/advantages-and-disadvantages-of-theworld-wide-web/

${ }^{3}$ Adapted from https://ipoint-tech.com/wireless-networking-wi-fi-advantages-and-disadvantages-to-wirelessnetworking/
} 
marked a turning point in terms of institutions seeing technologies shift from peripheral innovations to part of the core technical infrastructure provided to students.

\subsection{Mobile devices}

Increasingly, access to content and communicating with peers and family is done via mobile devices (smart phones, tablets and laptops), to such an extent that many predict the death of desktop computers in the near future. ${ }^{4}$ Mobile devices are relatively cheap now, generally have good screen interfaces, enable alternatives to keyboard input such as touch and voice input (particularly useful for those with accessibility problems and low-literate users). The advantages of mobile devices include: being able to access information and to communicate anywhere and anytime. Furthermore, there are now many sites and Apps for entertainment from simple Apps enabling a user to play card games, to Apps enabling you to play games with others online, to Apps given you access to audio and video (for example Netflix). Other benefits include online banking and shopping, safety in terms of individuals being able to call for help in an emergency and taking photographs to record special events. ${ }^{5}$

\subsection{OER and MOOCs}

UNESCO argues that education is a fundamental human right and essential for the development of society and eradication of poverty and low literacy skills. ${ }^{6}$ As such organisations like UNESCO and the Hewlitt foundation have been active promoters of the development and use of OER. The announcement of MIT that it was making a significant amount of its course content available online was quickly followed by the development of the OpenLearn respository in the Open University UK. There are now literally thousands of high-quality OER repositories worldwide.

More recently the concept of MOOCs have emerged. Initiated through the Connectivism and Connective Knowledge (CCK08) MOOC in 2008, which aimed to harness the networking affordances of social media to facilitate connectivist learning (Siemens, 2005). Later organisational like EdX, Udacity and Coursera developed more didactic MOOCs, called xMOOCs, which were more individually focussed and consisted of interaction with resources and videos and feedback via e-assessment. OER and MOOCs are challenging traditional educational business models and resulting in the emergence of new ways of recognition of non-formal and informal learning (Witthaus et al., 2016).

\subsection{Social media}

O'Reilly (2005) used the term 'Web 2.0' to emphasis the more participatory nature of the new digital technologies that were beginning to emerge at that time. Since then the breadth and variety of Web 2.0 tools has expanding rapidly (Conole and Alevizou, 2010). Conole (2013) lists the characteristics of social media as: the ability to peer critique and openly comment on others peoples' work, tools to enable user-generated content, mechanisms and tools for collective aggregation, being part of a global, distributed community, creation of tailored digital personas and individualised digital identities. De Frietas and Conole (2010) also argue that there has been a shift in the use of tools, which emphasises the more

\footnotetext{
${ }^{4}$ https://www.russharvey.bc.ca/resources/isthedesktopdead.html

${ }^{5} \mathrm{http}: / / \mathrm{www}$.ibuzzle.com/articles/advantages-of-mobile-devices.html

${ }^{6}$ See for example
} 


\section{G. Conole}

participatory and communicative capabilities of new technologies. These enable content and information to be distributed in a variety of different ways and hence the nature of content, both in terms of production and distribution, has shifted with greater control for the individual as producer and user.

\section{The characteristics of transformative technologies}

\subsection{Access to rich interactive resources}

A key feature of the web is that it provides access to an abundance of information; arguably anything you need to know is available on the web. This has resulted in a shift from a situation where knowledge is expensive and privileged to an 'ecology of abundance' (Weller, 2011a). This had profound implications, particularly in the developing world in terms of giving people access to an unprecedented amount of information. Carr (2008) argues that:

As the Internet becomes our universal medium, it is reshaping what might be called the economics of culture. Because most common cultural goods consist of words, images, or sounds, which all can be expressed in digital form, they are becoming as cheap to reproduce and distribute as any other information product. Many of them are also becoming easier to create, thanks to the software and storage services provided through the Net and inexpensive production tools like camcorders, microphones, digital cameras, and scanners.... The shift from scarcity to abundance in media means that, when it comes to deciding what to read, watch, and listen to, we have far more choices than our parents or grandparents did.

Weller (2011a) argues:

The economic model which has underpinned many content based industries has been based on an assumption of scarcity. With a digital, open, networked approach we are witnessing a shift to abundance of content, and subsequently new economic models are being developed which have this as an assumption.

\subsection{Immediacy}

Coupled with the fact that digital technologies enable learners to have access to rich interactive resources is the immediacy of technologies; i.e. access to knowledge is immediate. The answer to virtually anything is only a Google click away. Tapscott (1994) describes the 'age of network intelligence' as all encompassing and revolutionizing arising from today's digital technologies and their associated affordances. He argues that this new age is forcing us to rethink the traditional definitions of economy, wealth creation, business organisations and other institutional structures. He says this offers immense possibilities but also dangers. Mobile devices, good connectivity and SMS mean we can access information immediately and keep constantly in touch. A downside of this is that we are awash with information, arguably drowning in a sea of information and particular digital literacy skills are needed to find valuable resources amongst the 'white noise' created through a plethora of communication tools.

\subsection{Communication and collaboration}


Digital technologies offer a rich variety of ways in which learners can communicate with peers and tutors, and enables them to be part of a global community. The horizontal affordance of social media is resulting in a breaking down of hierarchies so that learners feel more empowered to connect with experts. Dialogic learning and collaboration are well known as important ways in which we learn. Communication with peers and tutors enables learners to articulate their understanding and offers opportunities for co-construction of knowledge and allow teachers to provide feedback to develop understanding. Bandura (1997) developed a social learning theory which argued that people learn from each other via observation, imitation and modeling. The dialogic relationship between learners and teachers is nicely illustrated in Laurilllard's Conversational Framework (1993). It is derived from Pask's conversation theory (Pask 1975), which centres on the idea that learning occurs through conversation and the notion of 'teachback' where one person teaches another what they have learned. This is related to, but distinct from, the concept of vicarious learning, which Cox et al. (1998) define as:

The potential benefits to learners of being able to observe or 'listen in' on experts or their peers as they discuss a new topic (p. 432).

Laurillard (1993) describes the stages involved in the dialogic interaction between a teacher and student, demonstrating the way in which concepts are internalized and adapted by each in the process (Figure 2).

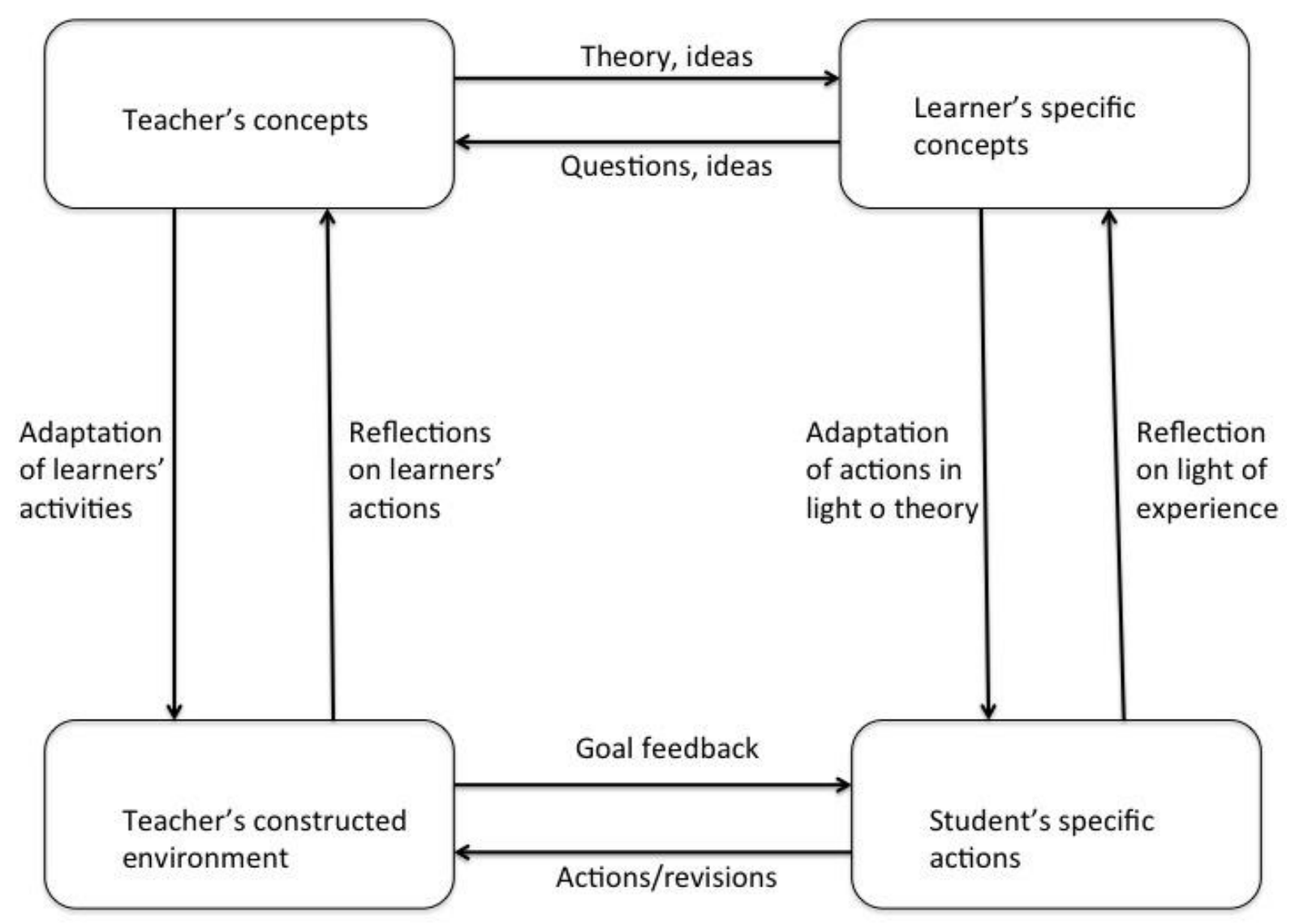

Figure 2: Adapted from Laurillard's Conversational Framework

Collaborative learning is where two or more people work towards a shared goal and learner together. The benefits are that they can learn from each other, utlising each other's skills and 


\section{G. Conole}

resources, and reflecting on each other's understanding. At the simplest level collaborative learning can be defined as learners working together to achieve a joint learning goal or outcome. Jones et al. (2007) make a distinction between the terms collaboration and cooperation. They reference Topping, who defined cooperation by studying its roots.

CO- means together in company, jointly, in common, equally, mutually, reciprocally, while OPERATE means to work, act, influence, effect, accomplish, cause or carry out (Topping 1992:151).

Dillenbourg (1999) distinguishes between cooperation and collaboration in the following way.

In cooperation, partners split the work, solve sub-tasks individually and then assemble the partial results into the final output. In collaboration, partners do the work 'together.' (p. 8)

Collaboration is a process by which individuals negotiate and share meanings relevant to the problem-solving task at hand.... Collaboration is a coordinated, synchronous activity that is the result of a continued attempt to construct and maintain a shared conception of a problem.

\subsection{Open practices}

One of the ways in which digital technologies, and particularly social media, have transformed learning, teaching and research is by enabling more open practices. Open practices refers both to the growth of free resources (Open Educational Resources) and courses (Massive Open Online Courses), but also to the ways in which through digital technologies our practices and discourses can be more visible.

Teacher and research presence is more visible through social media, from asking questions, developing ideas and sharing resources using tools like Twitter, Facebook and LinkedIn. Blogging can be particularly beneficial for scholarly discourse (Weller, 2011b) and reflection and the extent of reach through social media is exponentially greater than through traditional forms of dissemination.

In summary, there are three facets to openness. Firstly, because increasingly academic outputs are digitised they can be made available to a far greater audience than ever before. Secondly, networking - academics are now part of a global, distributed community of peers. Thirdly, open - in addition to the technical aspects of the concept of openness (such as open source software, open standards, open access and Open Educational Resources), new technologies are enabling more open practices. We are beginning, for example, to see a shift from publication in closed journals or books to more open practices of sharing research outputs via blogs and other open platforms.

\subsection{Portability across devices and locations}

Two factors are important in terms of portability, the increased prevalence of mobile devices and the emergence of cloud computing. Particularly through cloud computing resources can be made available across a range of devices. For example, purchasing an electronic EnglishSpanish dictionary through iTunes means the resources can be made available on an iPhone, 
iPad and Mac. Using tools such as Google drive means that documents can be available across different devices and locations and can be accessed by a group of people, facilitating collaborative writing. Another advantage of cloud computing is that it means data can be backed up automatically to the cloud. The exploring digital literacies in Higher Education project looked at students' engagement with and orientation towards digital technologies. ${ }^{7}$ The portability of students' personal digital devices (mobile phones, tablets) supports their spatial mobility and they frequently use these devices to read, make notes and find information. Pressed for time, students also use these mobile devices as opportunities to learn in 'downtimes', for example when travelling, sitting in the park, or relaxing in the bath. This portability, however, generates other issues: readability (screen size), access (connectivity, ability to download and store), health (tired eyes), etc.

\section{Challenges}

Despite the evident opportunities digital technologies offer learning, teaching and research there are challenges.

\subsection{The web and WI-FI}

In terms of the web and WI-FI, precisely because access is particularly ubiquitous, not having access is a major challenge. We expect to be able to be online all the time and not being online can have a severe impact on our productivity. Furthermore, there is an expectation from others that we will be online 24/7. This is particularly an issue with students, so it is important to set ground rules in terms of what they can expect as a reasonable turn around to a query they have and that they cannot expect to get a get an immediate reply to an email sent at $5 \mathrm{pm}$ on a Sunday.

\subsection{Learning Management Systems}

Learning Management Systems (LMSs) have been criticised for being too institutionally focussed, with tools (such as blog and wiki tools) often being sub-standard to those that are freely available on the web. A second criticism is that often the discussion and content generated in an LMS is not available post-course, or indeed from one year to the next on a course. This means that a student cannot go back and review content from a previous year. Furthermore if the evidence for achievement of learning is collated in an e-portfolio, which is then switch off after the course finishes the student cannot present this to potential employees, negating the concept of the development of lifelong learners. As a consequence the concept of Personal Learning Environments (PLEs) has emerged (Atwell, 2007). PLEs harness the affordances of social and participatory media (Conole, 2013) ${ }^{8}$ and enable learners to: set their own learning goals, manage their learning, both content and process and communicate with others in the process of learning. Learners can mix the tools available in their institutional LMS with freely available social media to create their own personalised learning environment. Those who are in favour of PLEs argue that they put the learner at the centre of the learning process, empowering them to take control of their learning.

\subsection{Mobile devices}

\footnotetext{
${ }^{7}$ http://libguides.ioe.ac.uk/c.php?g=482375\&p=3298534

${ }^{8}$ Such as adopting open practices, peer critiquing, distributed cognition, networking and collective intelligence
} 


\section{G. Conole}

Given the importance of mobile devices discussed earlier on, a key issue is battery life. Smart phones have increasing functionality, but this comes at a price in terms of the amount of memory needed and the impact on battery life. Even some modern smart phones need to be recharged often up to three times a day. As a counteraction to this Nokia has announced the return of the classic Nokia 3310, instantly recognizable, however it is sleaker and lighter than the original and will be available in a variety of colours. ${ }^{9}$ It has a range of basic functions for web surfing and taking pictures, but the key selling point is the battery life. Mobile devices are also fragile, it is very easy to crack the screen of mobile phones and iPads and replacement costs are not cheap, costing between 100 and 150 Euro. Finally, there may be issues with web pages not being rendered correctly, but this is increasingly less of a problem as sites are usually designed to be mobile friendly.

\subsection{OER/MOOCs}

Precisely because there is such a rich variety of resources available online finding relevant resources (OER and MOOCs) for a particular learning need can be problematic. In addition, once found evaluating the relevance and quality of the resource requires specialized digital literacy skills. MOOCs have been criticized for having very high drop out rates, some of the reasons cited for this are: the lack of support, participants (particularly in cMOOCs) are confused by the abundance of materials and the variety of ways of communicating, and the lack of a guided learning pathway. Finally, there is a lack of clarity in terms of how to recognized learning through OER and MOOCs, although new models are emerging, such as accreditation of OER provided by the OERu, ${ }^{10}$ and certificates of participation provided by FutureLearn. $^{11}$

\subsection{Social media}

Interaction through social media can exponentially increase the amount of access to information an individual has and degree of communication. Those active in social media sites like Twitter and facebook may often be connected to literally thousands of others worldwide. Amplification mechanisms such as retweeting and liking further extend the reach. Such high levels of interactivity can lead to significant confusion and cognitive overload and users often lack the necessary digital literacy skills to separate relevant information from the white noise. Groupthink is a psychological phenomenon that occurs within a group of people in which the desire for harmony or conformity in the group results in an irrational or dysfunctional decision-making outcome. ${ }^{12}$ Group members try to minimize conflict and reach a consensus decision without critical evaluation of alternative viewpoints by actively suppressing dissenting viewpoints, and by isolating themselves from outside influences. Nicols (2009) extends this idea to the digital context and argues that because of an amplification of certain information, there is a danger of a hegemonic approach, with valuable perspectives being lost.

\section{Researching digital learning}

\footnotetext{
${ }^{9}$ http://www.theverge.com/2017/2/26/14742150/nokia-3310-mwc-2017

${ }^{10} \mathrm{https}: / /$ oeru.org/

${ }^{11} \mathrm{https}: / /$ www.futurelearn.com/proof-of-learning/statement-of-participation

${ }^{12}$ https://en.wikipedia.org/wiki/Groupthink
} 
Having provided a backdrop in terms of key emergent transformative technologies, their characteristics and challenges this section will provide an overview of digital learning research.

Figure 3 illustrates the key components of researching digital learning.

\section{Researching digital learning}

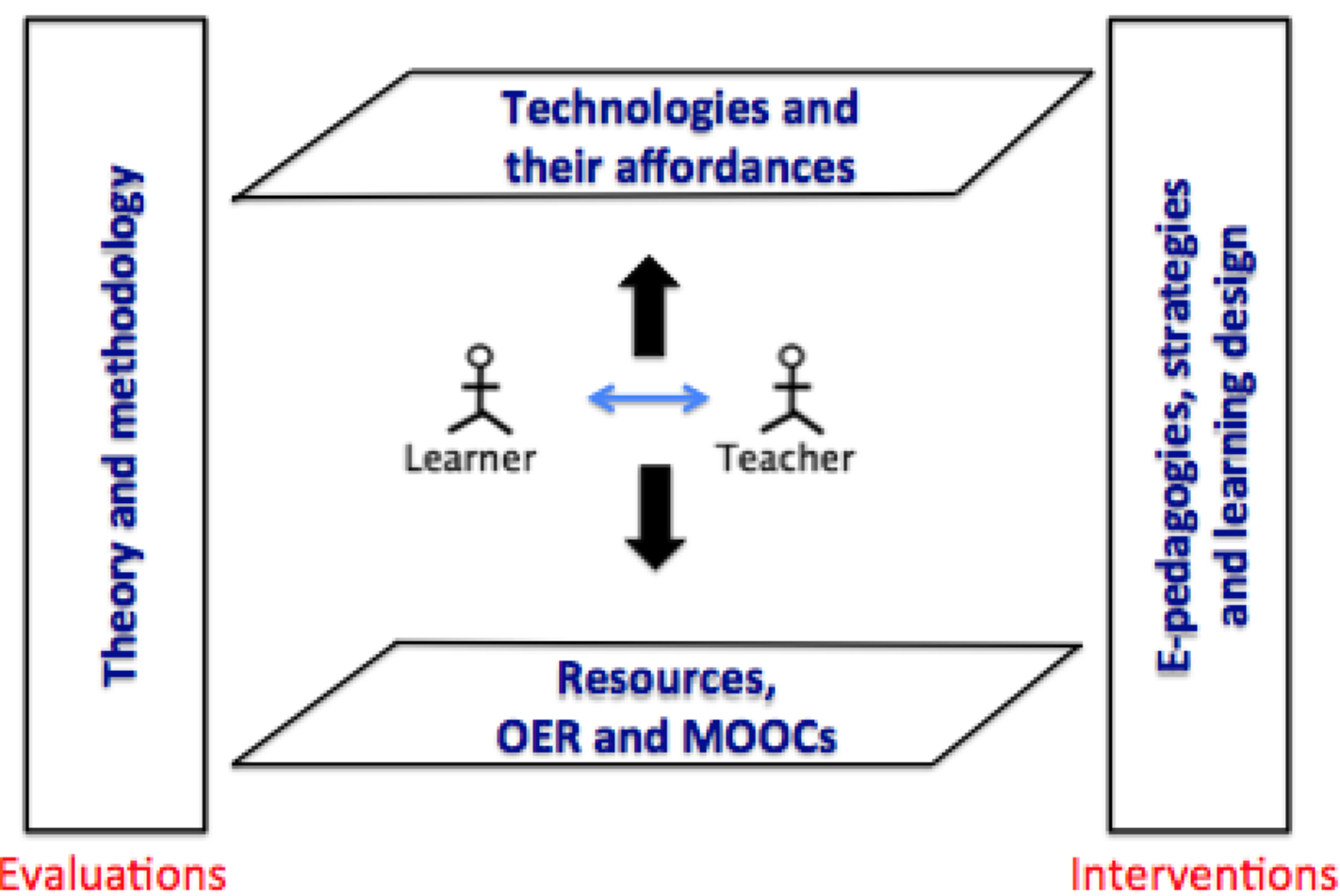

Figure 3: The key components of researching digital learning

At the heart of the figure are the key players, namely learners and teachers. It shows how they interact with resources, OER and MOOCs and engage with technologies and their associated affordances (Gibson, 1979; Conole and Dyke, 2004). The right hand side shows examples of the types of interventions that are possible, such as implementing different pedagogical approaches through the use of technologies, putting in place strategies for supporting digital learning or introducing new approaches to designing learning interventions. On the left hand side the evaluations of these interventions are show, including the methodologies used to collect and analyse data and the theoretical perspectives used to interpret them.

Figure 4 unpacks this a little more showing that digital learning research consists of three types: research around the pedagogies of digital learning, research on underpinning technologies, and research at an organizational level. 
G. Conole

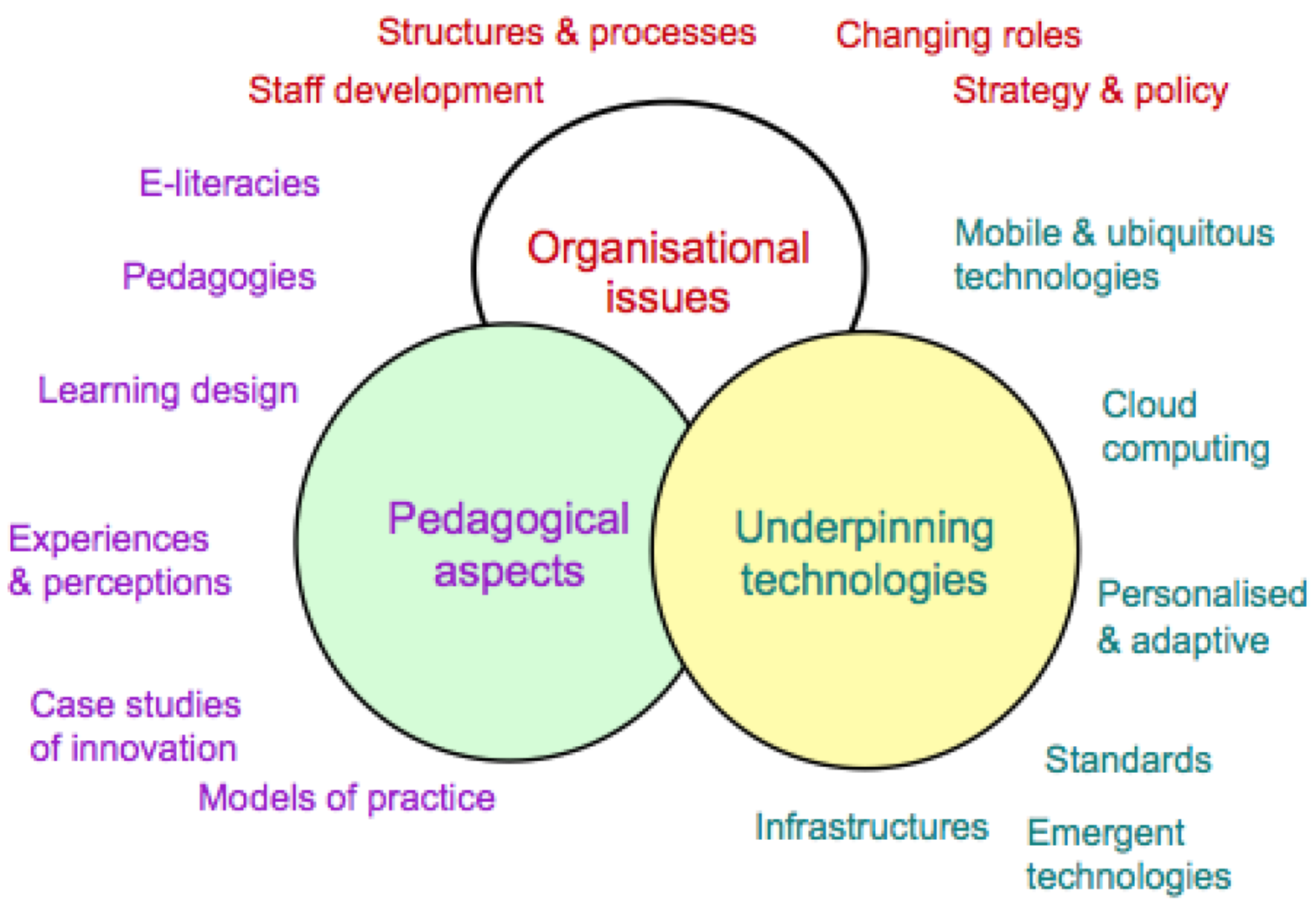

Figure 4: Facets of digital learning research

The emergence of a new research field can be classified as follows:

1. Pre-subject areas - no perceived interest

2. Beginnings - questions arising

3. Emergence - more researchers moving into the field

4. Diversification - different schools of thought, theoretical perspectives and methodologies emerge

5. Established - there is a defined community and alignment with other research fields.

In terms of this digital learning research is arguably between stages 4 and 5 for a number of reasons. Firstly, there have been an influx of researchers into the area over the last ten years or so. Secondly, there are now many established masters and $\mathrm{PhD}$ programmes on digital learning. Thirdly, there is a growth of dedicated research centres; such as the National Institute of Digital Learning at Dublin City University. Fourthly, there are numerous specialized journals and conferences on digital learning. Examples in Ireland include the Irish Journal of Technology Enhanced Learning and the established EdTech conference now in its $18^{\text {th }}$ year. Finally there is now a vibrant community of researchers using social media to discuss research ideas and to share resources.

Conole et al. (2010) carried out a research project looking at the nature of interdisciplinarity in digital learning research. They found that there were a variety of feeder disciplines, including: educational research, cognitive psychology, instructional design, computer science, business and management, philosophy, semiotics, and critical discourse analysis. The benefits of this were perceived to be the ability to draw on a wealth of methods and 
approaches and to look at research questions from different perspectives. The drawbacks were seen as the fact that there was no shared language or understanding, a lack of rigour, and little theoretical underpinning. It is also evident that the choice of research methodologies and methods will have an impact on the research outcomes. A criticism is that they tend to be based on previous experience and favoured methods, rather than experimenting with new approaches.

\section{Characteristics of digital learning research}

This section considers the characteristics of digital learning research. Conole and Oliver (2007) list six facets of e-learning research, which are also relevant for digital learning research. These are: the dynamically changing nature of the field, the inherent political nature of the field, the interdisciplinarity of the researchers, issues around inclusion and exclusion, the highly interactive nature of the area, and finally distilling out critical discourse from hype. Six themes of digital learning research are discussed: the good and the bad of digital technologies, the speed of change, new forms of discourses and collaborations, the importance of adopting a user focus, the changing nature of practice and finally the importance of and wider impact of digital learning research.

\subsection{The good and the bad of digital technologies}

Any critique of digital technologies shows that in addition to the perceived advantages there are also disadvantages. Five examples that illustrate this are:

1. The tension between institutional versus open systems

2. The affordances of technologies and how fit they are for purpose

3. The issue of copyright and ownership

4. How to simplify the complex

5. The balance between content and activities.

\subsection{Speed of change}

Technologies are constantly changing and as users appropriate technologies into their everyday practices how they use the technologies change. We are constantly seeing a new wave of tools and resources being developed, including the use of generic tools and resources, as well as those that have been specifically developed for an educational context. As mentioned earlier we are seeing an 'ecology of abundance' which means a description based on economic models is no longer appropriate; an ecological perspective better describes the dynamic and changing nature of the interface of users and technologies. Particularly useful in this respect is the concept of rhizomatic learning. Cormier (2008) describes how a rhizomatic plant has no centre and no defined boundary; rather, it is made up of a number of semi-independent nodes, each of which is capable of growing and spreading on its own, bounded only by the limits of its habitat. He goes on to state that in a rhizomatic view of learning, knowledge can only be negotiated, and the contextual, collaborative learning experience shared by constructivist and connectivist pedagogies is a social as well as a personal knowledge-creation process with mutable goals and constantly negotiated premises. Given the constant nature and speed of change, it is impossible to predict the 


\section{G. Conole}

unpredictable (Naughton, 2012). Related to this is Castell's notion of 'informed bewilderment.

The 21st century will not be a dark age. Neither will it deliver to most people the bounties promised by the most extraordinary technological revolution in history. Rather, it may well be characterised by informed bewilderment. (1999: 4)

Finally we are seeing a blurring of boundaries: of real and virtual, of teacher and learner, of formal and informal.

\subsection{New discourses and collaborations}

Digital technologies offer a plethora of ways in which learners can communicate and collaborate and we are seeing new rich and distributed learning communities. The way in which we interact with digital technologies can be a form of distributed cognition, i.e. that knowledge is not confined to an individual but is distributed across objects, individuals, artefacts, and tools in the environment (Salomon, 1993) and the related concept of Person Plus (Perkins, 1993). As previously discussed, interaction and communication through social media can be confusing and individuals need to develop the necessary digital literacy skills to make sense of all this information, through the use of filtering mechanisms and curation, and through tailoring and contextualisation - what is relevant to one person will not necessarily be relevant to another. Finally, new forms of digital literacies and metaphors of understanding are needed to make sense of this complex new world.

\subsection{The importance of understanding users}

Never before has it being more important to understand users, how they interact with technologies and their expectations and perspectives of technologies. This is in part because of the individualized nature of interaction with technologies; the potential for adaptivity and personalization. To address this ethnographic approaches are particularly useful, as is DesignBased Research and the notion of the perpetual beta (Jarche, n.d.). This is important as we are developing for the unknowable.

\subsection{Changing practice}

We are seeing changes in practices as a result of interaction with digital technologies. More open and reflective practices through social media mean researchers can be much more reflective practitioners. Bonk et al. (2015) provide a summary of MOOCs and open education. Key themes from across the chapters are that it is clear that digital technologies enable more open practices, and we are seeing the increasing importance of OER and MOOCs. We are seeing roles changing. The Internet has not resulted in the death of teachers, their role is more important than ever, but there is a shift from knowledge transmission to digital curation, designing effective learning interventions using technologies, and facilitating learning. We are also seeing new organisations structures and processes, and new business models are emerging.

\section{Conclusion}


This paper has provided an overview of the field of digital learning, highlighting some of the benefits of using technologies to support learning, along with some of the challenges. To summarise Figure 5 visualizes the relationship between digital learning research and practice, resources, learning, technologies, strategy, policy, theory and development.

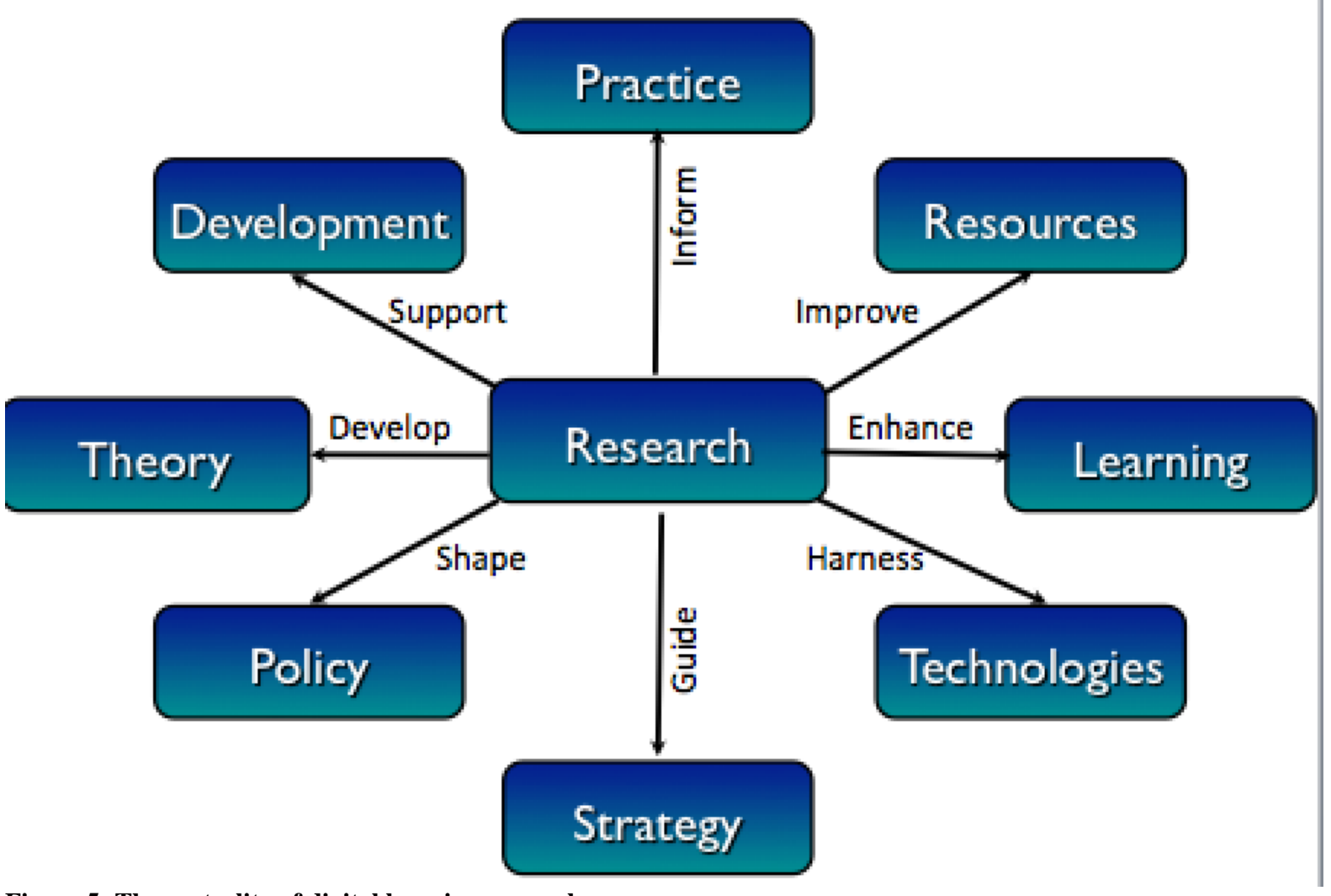

Figure 5: The centrality of digital learning research

To conclude, it is worth stating that research in digital learning is essential, technologies are fundamental tools for learning and cannot be ignored. In terms of the wider impact and extrapolation of what is known now from the research, there are five aspects: the emergence of new models for education, a blurring of boundaries (spaces, roles, etc.), the value of ways to support compelling experiences and facilitate productive failure, and understanding that we operate in an uncertain world with a future we cannot imagine. We are seeing an unbundling of education, where learners in the futures may not choose to do formal threeyear degrees but may opt to pay for: quality content, guided learning pathways, support or accreditation. Finally, technologies are here to stay and their impact on learners, on teachers and on institutions is likely to continue to have a significant and increasing impact.

Figure 6 argues that digital learning can be best enabled through effective approaches to designing for learning and through effective use of learning analytics. 
G. Conole
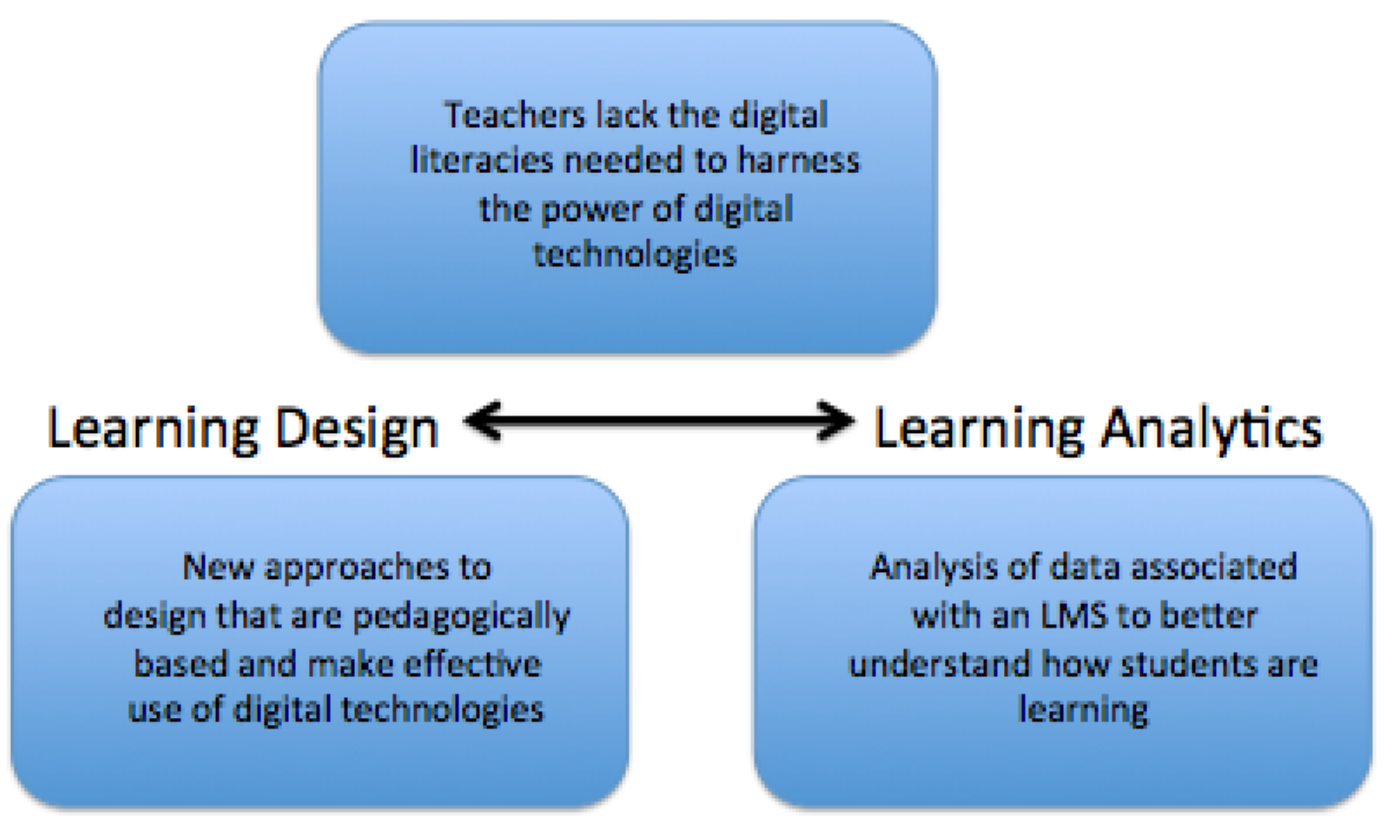

Figure 6: Enabling digital learning

The take home messages are that this is an exciting and important time for digital learning research, there are multiple theoretical research perspectives and methodologies, which have enormous potential but must be appropriately used. The papers has described some of the challenges, such as the balance of 'noise'/relevance, finding quality resources, fragmented identities, new digital literacies, the need for professional development and the impact on assessment practices. Finally, two key questions to reflect on: what are the key research questions we need to address moving forward, and how do we ensure the rich research findings from the field of digital learning research have an impact on policy and practice? 


\section{References}

Atwell, G. 2007, Personal Learning Environments: the future of learning?, eLearning papers 2(1).

Bandura, 1977, Social Learning Theory, New York: General Learning Press, available online at http://www.esludwig.com/uploads/2/6/1/0/26105457/bandura_sociallearningtheory.pdf

Bonk, C.J., Lee, M.M., Reeves, T.C., and Reynolds, T.H. 2015, MOOCs and open education around the world, London: Routledge.

Carr, N. 2008, The great unbundling: newspaers and the Net, post post on Encyclopedia Britannica blog, posted on 7/4/2008, available online at http://blogs.britannica.com/2008/04/the-great-unbundling-newspapers-the-net/

Castells, M. 1999, The rise of the networked society: The Information Age: Economy, Society and Culture, Third Volume, London: Wiley Blackwell.

Christensen, C. 1997, The innovator's dilemma: When new technologies cause great firms to fail, Harvard: Harvard University Press.

Conole, G., 2013, Designing for Learning in an Open World, London: Sringer.

Conole, G. and Dyke, M. 2004, What are the affordances of information and communication technologies?, ALT-J, Vol. 12, No. 2, available online at http://files.eric.ed.gov/fulltext/EJ821518.pdf

Conole, G. and Oliver, M. 2007, Contemporary perspectives in e-learning research, London: Routledge.

Conole, G., and Alevizou, P. 2010, Review of the use(s) of Web 2.0 in Higher Education. Retrieved from http://cloudworks.ac.uk/cloudscape/view/1895

Conole, G., Scanlon, E., Mundin, P. and Farrow, R. 2010, Interdisciplinary Research:

Findings from the TEL Research Programme. TEL Programme. Dogan, M., and Pahre, R.

Cormier, D. 2008, Rhizomatic Education: Community as Curriculum, Innovate: Journal of Online Education: Vol. 4: Iss. 5, Article 2. Available at:

http://nsuworks.nova.edu/innovate/vol4/iss5/2

Cox, R., McKendree, J. and Mayes, T. 1998, Vicarius learning from dialogue and discourse: a controlled comparison, Netherlands: Kewer Academic Publishers.

Deák, G.O. 2014, Interrelations of language and cognitive development. Encyclopedia of Language Development (pp. 284-291). P. Brooks \& V. Kampe, Eds. SAGE, available online at

http://cogdevlab.ucsd.edu/files/2014/09/Deak_Ency_Lang_Dev_Relation_Lang_Cog_Dev_2 014.pdf 


\section{G. Conole}

De Freitas, S., and Conole, G. 2010, Learners experiences: how pervasive and integrative tools influence expectations of study, 15 - 30, in R Sharpe, H. Beetham and S. De Freitas (Eds), Rethinking learning for a digital age: how learners are shaping their own experiences. London: Routledge

Dillenbourg, P. 1999, What do you mean by collaborative learning. Collaborativelearning: cognitive and computational approaches. P. Dillenbourg. Oxford, Elsevier: 1 19.

Ferguson, F. 2013, Learning analytics: drivers, developments and challenges, International Journal of Technology Enhanced Learning, 4(5/6) pp. 304-317, available online at http://oro.open.ac.uk/36374/1/IJTEL40501_Ferguson\%20Jan\%202013.pdf

Gee, P. 2003, What video games have to teach us about learning and literacy, New York: Palgrave/Macmillan.

Gibson, J. J. 1979, The ecological approach to visual perception. Hillsdale, New Jersey: Lawrence Erlbaum Associated.

Henry, A. 2014, Five best language translation tools, lifehacker blog, 14/9/2014, available online at http://lifehacker.com/five-best-language-translation-tools-1634228212

Innovating Pedagogy 2016, Innovating Pedagogy 2016L exploring new forms of teaching, learning and assessment, to guide educators and policy makers, available online at http://proxima.iet.open.ac.uk/public/innovating_pedagogy_2016.pdf

Jarche, H. n.d., Books in beta - the perpetual beta series, blog post available online at http://jarche.com/services/books-in-beta/

Jones, C., J. Cook, A. Jones and M. De Laat, 2007, Collaboration, Chapter 12. Contemporary perspectives in e-learning. G. Conole and M. Oliver. London, RoutledgeFalmer.

Laurillard, D. 1993, Rethinking University Teaching: A Conversational Framework for the Effective Use of Learning Technologies, London: Routledge.

McLuhan, M. 1964, Understanding media: the extensions of man, Cambridge, Massachusetts: MIT press, available online at http://teleensm.ummto.dz/pluginfile.php/201482/mod_resource/content/1/\%5BMarshall_Mc Luhan\%5D_Understanding_media(BookZa.org).pdf

Naughton, J. 2012, From Gutenberg to Zuckerberg: what you really need to know about the internet, London: Quercus.

Nicols, M. 2009, eGroupThink, invited talk, ASCILTE conference, Auckland.

NMC 2016, New Media Consortium 2016 Higher Education Edition, available online at http://cdn.nmc.org/media/2016-nmc-horizon-report-he-EN.pdf 
O'Reilly, T. 2005. What is Web 2.0 - Design patterns and business models for the next generation of software. http://oreillynet.com/pub/a/oreilly/tim/news/2005/09/30/what-is-web$\underline{20 . h t m l}$

Owston, D., Murphy, S., and Wideman, H.H. 1992, The effects of word processing on students' writing quality and revision strategies, Research in the Teaching of English, Vol, 26, No, 3 (Oct 1992), pp. 249 - 276.

Perkins, D.N. 1993. Person-plus: A distributed view of thinking and learning. In G. Salomon (Ed.), Distributed Cognitions: Psychological and educational considerations (pp.88-110).

Salomon, G. (Ed.). 1993. Distributed cognitions - pyschological and educational considerations. Cambridge: Cambridge University Press.

Siemens, G. 2005. Connectivism: A learning theory for the digital age. International journal of instructional technology and distance learning, 2(1), 3-10.

Tapscott, D. 1994, The digital economy promise and peril in the age of networked intelligence, London: McGraw-Hill.

Topping, K. 1992 Cooperative learning and peer tutoring: An overview, The Psychologist, 5, 151-161.

Weller, M. 2011a, A pedagogy of abundance. Spanish Journal of Pedagogy, 249 pp. 223236.

Weller, M. 2011b, Digital scholar: how technology is transforming scholarly practice, Basingstoke: Bloomsbury Academic, available online at https://www.bloomsburycollections.com/book/the-digital-scholar-how-technology-istransforming-scholarly-practice/.

Witthaus, G., Inamorato dos Santos, A., Childs, M., Tannhauser, A.C., Conole, G., Nkuyubwatsi, B. and Punie, Y., 2016, Validation of non-formal MOOC-based learning: an analysis of assessment and recognition practices in Europe (OpenCred), IPTS report, available online at

http://publications.jrc.ec.europa.eu/repository/bitstream/JRC96968/lfna27660enn.pdf 